\title{
APPLYING "SPARK PLASMA SINTERING" TECHNO-LOGY TO ENHANCE THE RESISTANCE TO CONTACT FATIGUE OF SINTERED STEEL BASED ON ASTALOY CRL
}

\author{
D. Rodziňák, J. Čerňan, V. Puchý
}

\begin{abstract}
The article deals with the effect of porosity on the contact fatigue of sintered material type Astaloy $\mathrm{CrL}$ with 0.3 and $0.4 \% \mathrm{C}$. Sets of samples were used with densities beginning from the value of $7000 \mathrm{~kg} . \mathrm{m}^{-3}$ to the value of almost $7859 \mathrm{~kg} . \mathrm{m}^{-3}$ which represents almost zero porosity (compact material). It has been found out that the increase of compacting pressure applied simultaneously with temperature results in the reduction of porosity from the value of $9.10 \%$ to $0.0005 \%$ and increase in hardness from 145 to 193 HV10, depending on the carbon content. Logically there is also an increase in the fatigue life by the contact fatigue tests for the value of $50 \times 10^{6}$ cycles from the value of $900 \mathrm{MPa}$ to $1150 \mathrm{MPa}$ for samples with $0.3 \%$ of C and from $900 \mathrm{MPa}$ to $1300 \mathrm{MPa}$ for samples with $0.4 \%$ C. These investigations were also carried out in the past, but to achieve the reduction of porosity, different technonologies were used at each level such as double pressing, hot pressing, saturation, hot forging, etc. In this case, the single technology of "spark plasma sintering" making use of compacting at high temperatures is capable to continuously reduce porosity to zero.
\end{abstract}

Kewords: spark plasma sintering, Cr-sintered steel, contact fatigue

\section{INTRODUCTION}

Our previous works [1-3] have already monitored the contact fatigue of sintered steels based on material type Astaloy $\mathrm{CrL}$ produced by Höganäs. They were investigating sintered materials with a density of about $7000 \mathrm{~kg} \cdot \mathrm{m}^{-3}$ using heat and chemical-heat treatment and based on known methods of enhancing the basic properties of sintered materials, of course. At a later stage we used such kinds of technologies which affected only the surface layers critical in terms of contact fatigue destruction. Here, for example, belongs the technology of laser hardening, or methods of applying hard thin coatings such as TiCN type or DLC type respectively to the surface layers [4-6]. In all the cases they did improve resistance to contact fatigue destruction. It is a matter of course that similar results have also been achieved by other authors whom we have not forgotten to cite in our articles. In all instances the use of sintered materials was bound to the density of 7000 $\mathrm{kg} \cdot \mathrm{m}^{-3}$, and it is well known that the porosity of such materials drastically reduces their mechanical properties.

\footnotetext{
Dušan Rodziňák, Jozef Čerňan, Faculty of Aeronautics, Technical university of Košice, Košice, Slovak Republic Viktor Puchý, Institute of Materials Research, Slovak Academy of Science, Košice, Slovak Republic
} 
The reduction of porosity is not a technical, but an economic problem. Earlier in the second half of last century, the US and Japan produced rolling bearings based on powder materials with (that have a reduced) porosity reduced virtually to zero. Our research laboratory confirmed this fact in 1986 in the paper [7] when after having applied pressing, sintering and subsequent forging to heated alloyed material, it managed to produce samples with immeasurable porosity, the fatigue life of which was comparable to conventional roller bearings.

Increasing the specific density is also possible today, but for each range of porousness a different technology is needed, a fact that increases costs and prolongs production time and assumes the use of other machinery and so on. Currently the SPS (spark plasma sintering) technology has been developed serving a general purpose, and it is possible to produce powder material with continuously varying porosity practically up to a compact state. The importance of these tests is simply to see whether this technology can bring better results in the future in cases where base material with very low porosity is needed. Such material will then be equally subjected to conventional methods of either heat or chemical-heat treatment, or the use of coating methods.

\section{EXPERIMENTAL}

The samples were prepared from pre-alloyed metal powder of the type Astaloy CrL (Fe- $1.5 \% \mathrm{Cr}-0.2 \% \mathrm{Mo}$ ) from Höganäs with a weighted addition of graphite powder of $0.3 \%$. From these prepared mixtures circular specimens $\phi 30 \mathrm{~mm}$ were molded. For compaction, the same amount of powder was still used. The basic set of the samples had a specific density $\gamma=$ $7000 \mathrm{~kg} \cdot \mathrm{m}^{-3}$, which corresponded to sample thickness of $5 \mathrm{~mm}$. Other sets were pressed to a higher specific density up until about zero porosity, which meant that the thickness of the samples was becoming smaller with pressure increasing. The dimensional factor, however, has not affected the test results. Tab.1shows what set of samples were tested, under what conditions and what their basic characteristics were. To this purpose an SPS-type device, the HP D10-SD model (FCT - Systeme GmbH, Germany, was used applying the technology known as "spark plasma sintering". The principle of this technology is clear from Fig 1a. It is based on hot pressing in a carbon matrix, where two modes of sintering are possible. In the first mode, pulsed electric current passes only through a carbon matrix, and thus it is heated up to the selected sintering temperature. The second mode uses the flow of current through the conductive sintered material, causing the "welding" of the individual particles of the powder material, making the process of sintering more effecient. So, we have made use of both operating modes of the equipment. In our case, the compacting pressure was selected in the range of $20-60 \mathrm{MPa}$ at a constant temperature of $1120^{\circ} \mathrm{C}$. To avoid carburization of the samples, woven fabric of glass fibers were used for the walls of the carbon matrix, which do not allow direct contact of the compressed powder with the carbon matrix. In some cases however, it came to an increase of carbon content to $0.4 \% \mathrm{C}$. These samples and the results have also been included in the evaluation. The compression as it takes place is shown in Fig. 1b. Also shown in the figure are the behaviours of the parameters which are important in the process management, particularly those of the pressure and temperature. More detailed descriptions of this method and its applications are dealt with in adequate publications and references such as [8-10].

The molded samples were then mechanically machined to the external dimension of $\phi 28 \mathrm{~mm}$, with an internal hole of $\phi 10 \mathrm{~mm}$ and polished to achieve the flatness of the two circular areas. Tests on the contact fatigue were carried out on the AXMAT device (Fig.1b) the frequency cycles of which were 500 cycles/min. The sample in AXMAT replaces one part of the thrust bearing type 51102, and with 12 balls of $\phi 3.969 \mathrm{~mm}$ bearing 
steel rolling across its surface in a cage. Lubrication is ensured by a continuous supply and filtration of MOGUL SAE 80 gear oil. A more detailed description of this method is given in our previous publications [1-3].

The evaluation of contact-fatigue tests was based on the diagrams of S-N curves plotted. As a comparator the lifetime of $50 \times 10^{6}$ cycles was used. The evaluation classical chemical analysis for determination of carbon content of other values was used. To determine the structure of individual samples, a metallografic-microscopic analysis was used along with a surface analysis of the share of individual structural components in order to verify carbon content. In addition, the SCAN microscope with EDX analysis was used. The hardness was measured by Vickers method. The density of the samples was determined by double weighing and after conversion helped to determine porosity. Metalograficmicroscopic monitoring of relevant events or facts was a matter of course.
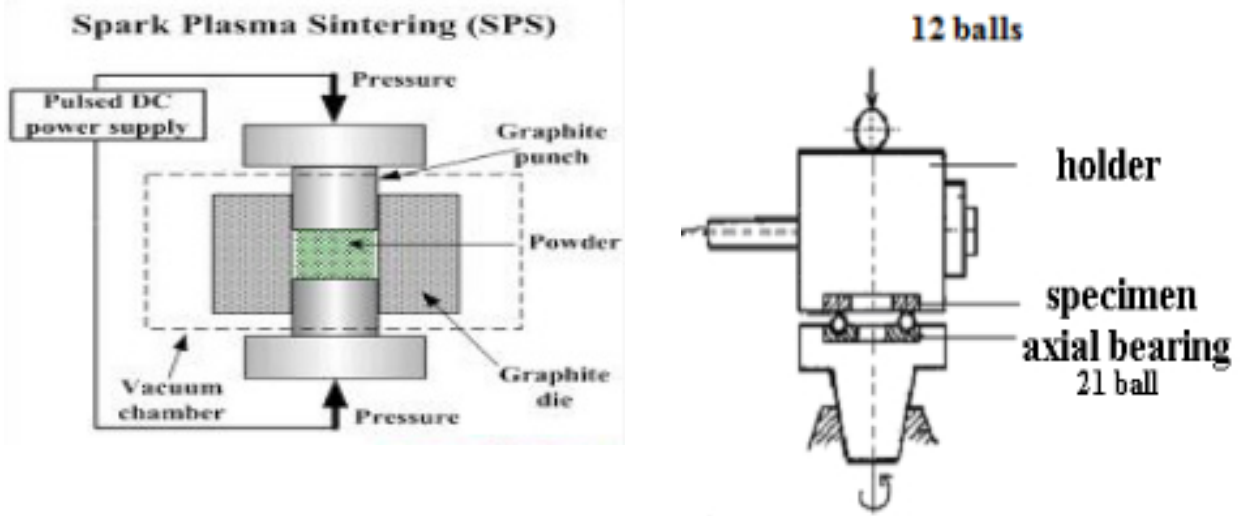

Fig.1 Principle of: a) Plasma Spark Sintering, b) AXMAT device.

\section{RESULTS}

As it is clear from Table 1 and the accompanying graphs, modification of porosity occurs due to the amount of compacting pressure, and to the change of mechanical properties - Fig. 2 and 3. In this case of course, it is only the quantification for the current conditions. At the same time, it can be stated that under the given conditions (especially at the temperature $1120^{\circ} \mathrm{C}$ ), practically zero porosity can be achieved. Fig. 4 a,b shows the structure of the following sintered steel with $0.4 \% \mathrm{C}$ at a compacting pressure of $20 \mathrm{MPa}$, representing a density of about $7000 \mathrm{~kg} \cdot \mathrm{m}^{-3}$, which also corresponds to a porosity of $10.94 \%$. The increase of compacting pressure to $60 \mathrm{MPa}$ with other unchanged conditions will result in full compactization with the density $7859 \mathrm{~kg} \cdot \mathrm{m}^{-3}$, corresponding to the porosity $0.005 \%$. In all cases, the structure was of the ferritic-perlitic, which means that at cooling the conditions of equilibrium have been observed.

The results of contact fatigue are listed in Table.1, as well as on the graph of Fig. 6. It is evident that as porosity decreases, resistance to contact fatigue increases, manifested by the emergence and spread of pittings. Depending on the carbon content, within the density range of $7000 \mathrm{~kg} \cdot \mathrm{m}-3$ to density of $7859 \mathrm{~kg} \cdot \mathrm{m}^{-3}$, lifetime value increased from 900 to $1300 \mathrm{MPa}$. This result has to be confronted with results that have been achieved not only by us, on the material with the said contents of carbon, made in the traditional manner by 
way of cold pressing followed by sintering, both at the same sintering temperature of 1120 ${ }^{\circ} \mathrm{C}$. The values published $[\underline{1,2,11]}$ fell in the range of about $650-900 \mathrm{MPa}$.

Tab. 1 Properties of the investigated materials.

\begin{tabular}{|c|c|c|c|c|c|c|}
\hline $\begin{array}{c}\text { Sample } \\
\text { No. }\end{array}$ & $\% \mathrm{C}$ & $\begin{array}{c}\text { Compacting } \\
\text { pressure } \\
(\mathrm{MPa})\end{array}$ & $\begin{array}{c}\text { Hardness } \\
\text { HV10 }\end{array}$ & $\begin{array}{c}\text { Density } \\
\left(\mathrm{kg} . \mathrm{m}^{-3}\right)\end{array}$ & $\begin{array}{c}\text { Porosity } \\
(\%)\end{array}$ & $\begin{array}{c}\text { Contact Fatigue life } \\
\sigma_{\mathrm{C}}(\mathrm{MPa})\end{array}$ \\
\hline 1 & 0.3 & 40 & 160 & 7720 & 1.76 & 900 \\
\hline 2 & 0.3 & 50 & 168 & 7750 & 1.39 & 1000 \\
\hline 3 & 0.3 & 60 & 175 & 7825 & 0.44 & 1150 \\
\hline 1 & 0.4 & 20 & 145 & 7001 & 10.94 & 900 \\
\hline 2 & 0.4 & 30 & 160 & 7045 & 5.19 & 1200 \\
\hline 3 & 0.4 & 40 & 173 & 7710 & 1.97 & 1250 \\
\hline 4 & 0.4 & 60 & 193 & 7859 & 0.0005 & 1300 \\
\hline
\end{tabular}

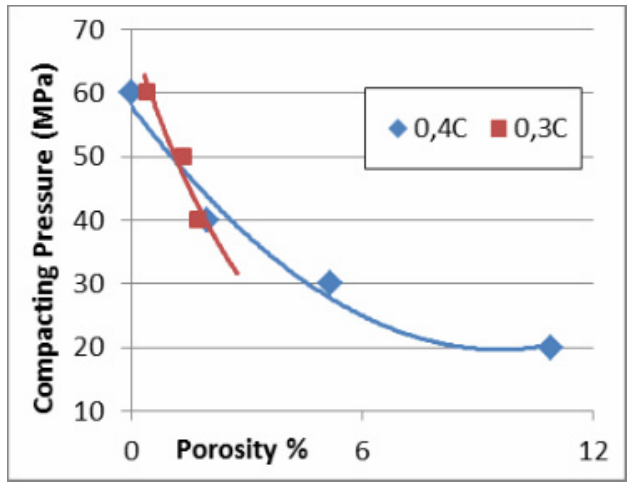

Fig.3. Compacting Pressure versus porosity

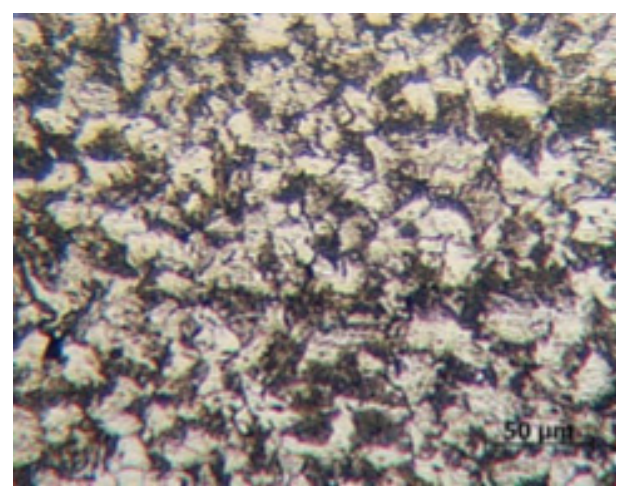

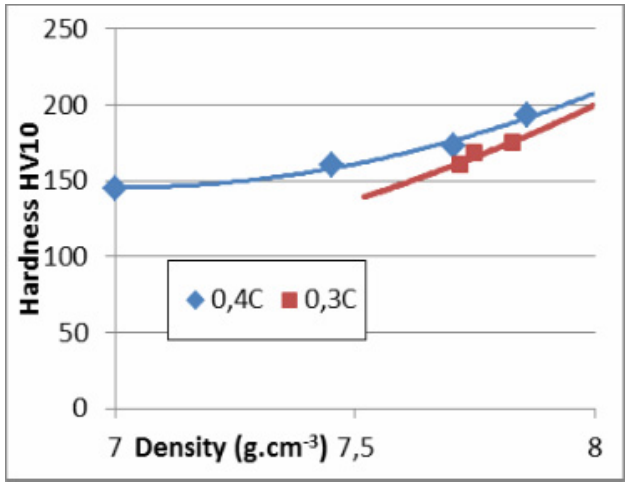

Fig.4. Hardness HV 10 versus density

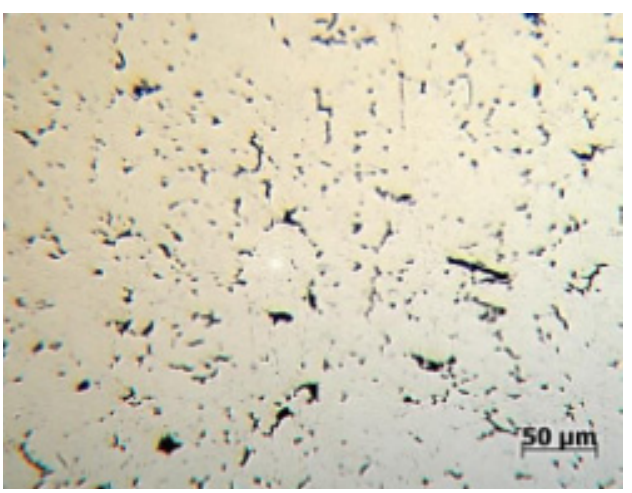

Fig.4 Ferritic-pearlitic microstructure of Astaloy $\mathrm{CrL}$ with $0.4 \% \mathrm{C}$ - etched and non-etched state with density of $7000 \mathrm{~kg} \cdot \mathrm{m}^{-3}$. 

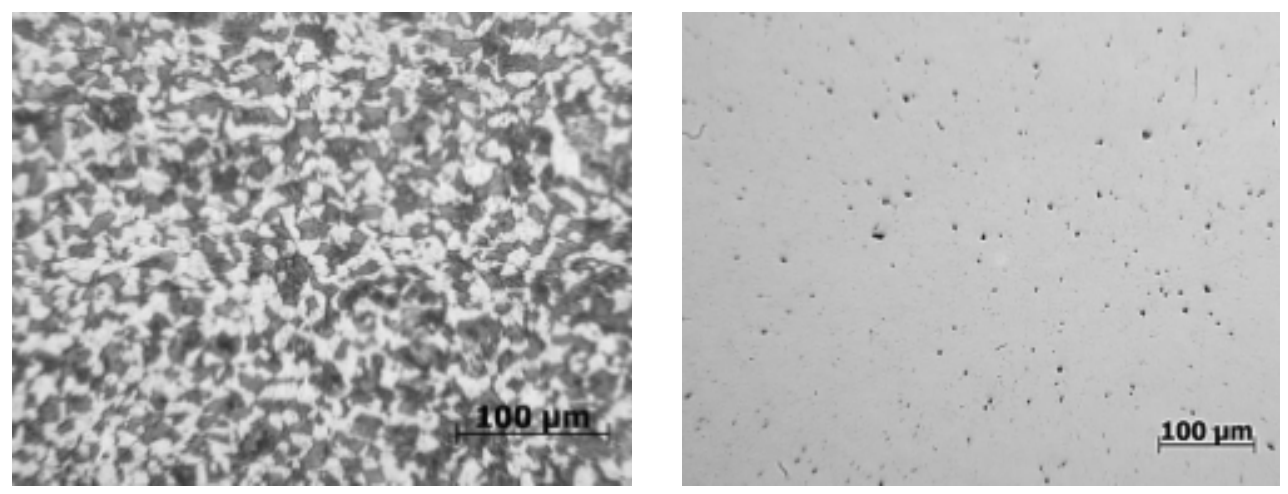

Fig.5 Ferritic-pearlitic microstructure of Astaloy $\mathrm{CrL}$ with $0.4 \% \mathrm{C}$ - etched and non-etched state with density of 7859 g.cm ${ }^{-3}$.

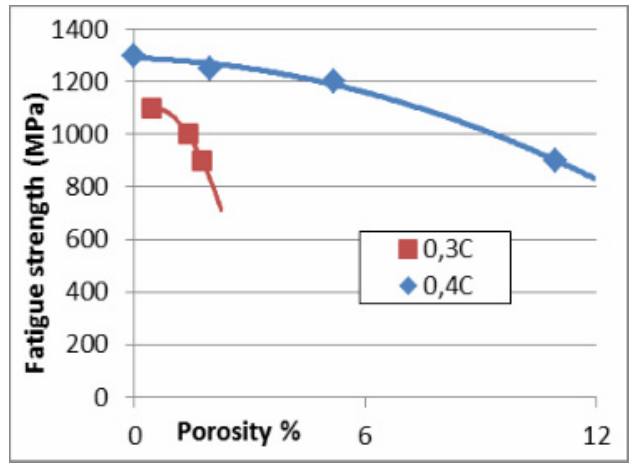

Fig.6 Fatigue strength versus porosity of specimens.

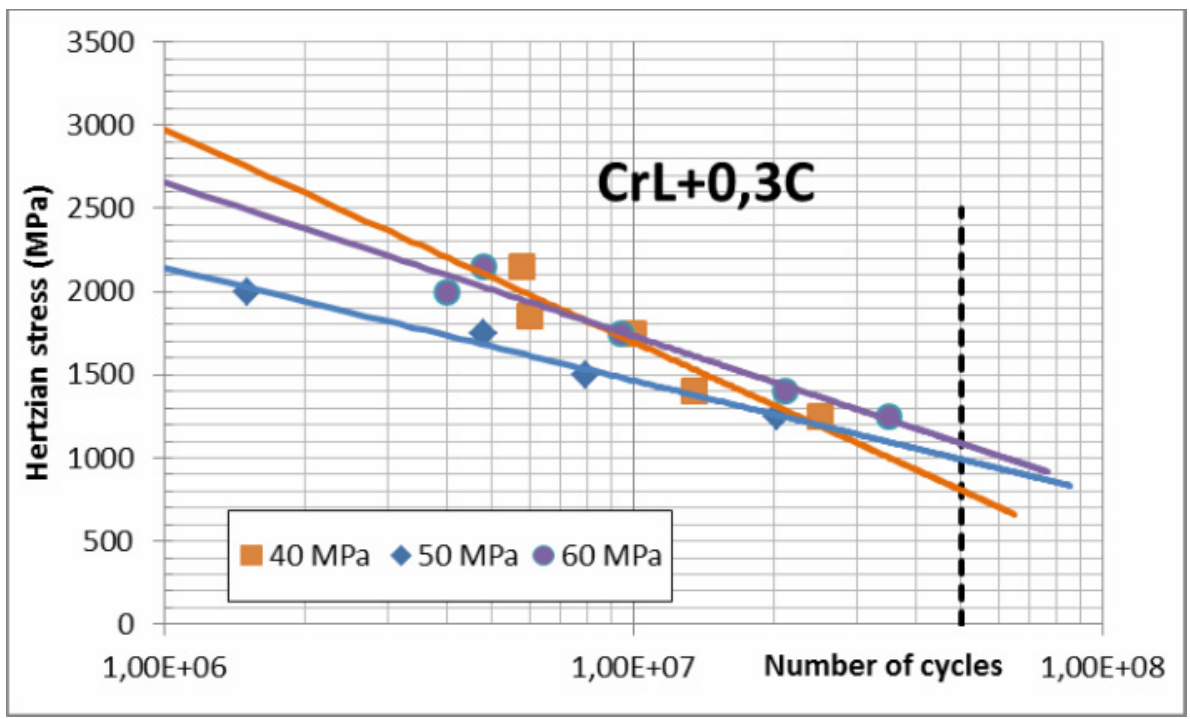

Fig. 7 S-N curves for material with $0.3 \% \mathrm{C}$ moulded by compacting pressures of 40,50 , $60 \mathrm{MPa}$. 


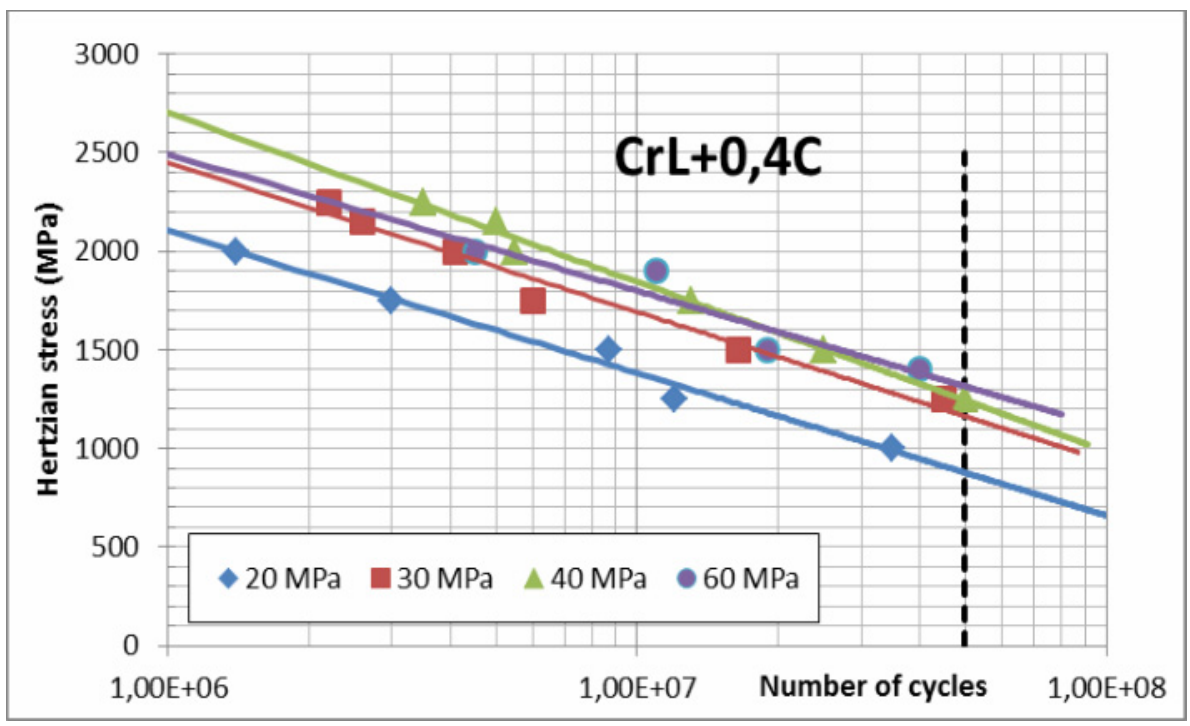

Fig. 8 S-N curves for material with $0.4 \% \mathrm{C}$ moulded by compacting pressures of 20, 30, 40, $60 \mathrm{MPa}$.

As a result of rolling contact fatigue wear, pittings or craters have developed on the tested samples. Similar to the general observation regarding formation of pitting on sintered materials, even in this case several pittings have been developed in the wear orbit, as well. Owing to the stress-deformational conditions, crackings appeared in the areas of the pores, mostly spreading at angles between 30-40 degrees. Consequently, development of a larger number of pittings can be regarded as an attribute of sintered porous materials. By contrast, in compact materials only one pitting is formed, mainly on the surface. This is similar to the classic fatigue phenomenon. The mechanism of developing pitting also varies, of course. For compact materials the mechanism of formation is determined by the Hertzian theory, by which the maximum stress in the material subjected to contact stress is developing underneath its surface at a depth of $x=0.4 . b$ (where $b$ is the width of the contact area), the very location where rupture occurs. Subsequently, both ends of the crack are turning towards the surface. Upon reaching it, the material gets separated, and the pitting is formed. Our observation of this phenomenon during our research confirmed this fact, although partially. Porous materials developed relatively large amount of pittings in the orbit - logically at places of the pores. On compact materials just one pitting was formed but their number was lower, when treated under the same conditions - (a roughly similar number of cycles between failures) - Figure $9 a, b$.

Logically, we assumed that on material with virtually zero porosity pitting will be developed from the cracks under the surface initiated by stress, this in compliance with the Hertzian contact theory. This assumption has proved to be reflected only partly. Microscopic observation of sections perpendicular to the orbit revealed the existence of two mechanisms of developing cracks. Fig. 10 shows that below the surface in the depth of $x$ corresponding to the maximum stress, leads to formation of a crack running parallel to the surface. In Fig. 10 b, the rupture started from the surface as a result of higher stress at the root of the pore. This is so because in the case of zero porosity there are still arous found on the surface which are not perfect. And vice versa, many pores can be pressed, but it need not come to a perfect contact. 


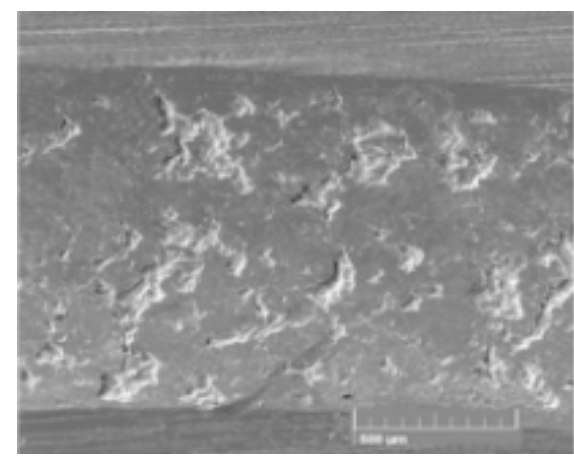

Fig. 9a Pittings on material with density of $7000 \mathrm{~kg} \cdot \mathrm{m}^{-3}$.

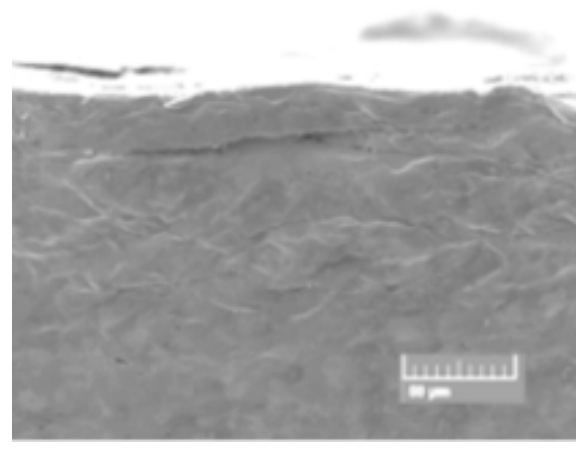

Fig. 10a) The development of subsurface cracks in epicentre of maximum Hertzian stress.

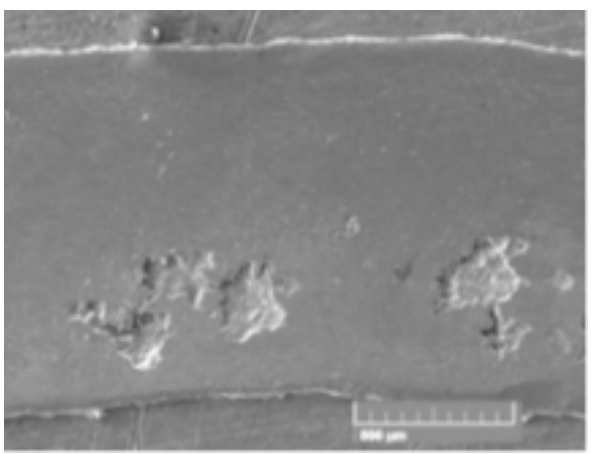

Fig. 9b Pittings on material with density of $7859 \mathrm{~kg} \cdot \mathrm{m}^{-3}$.

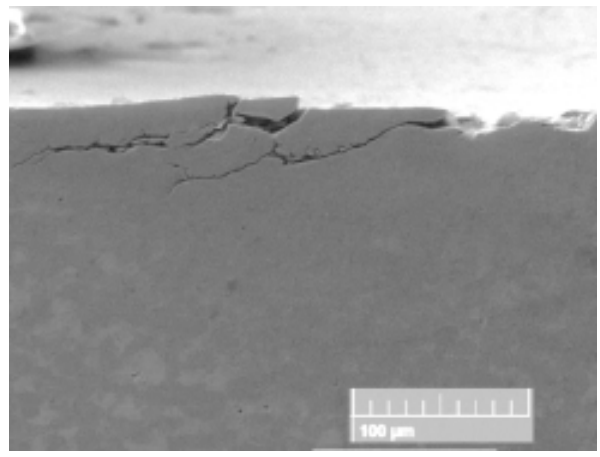

Fig. 10b) Cracks developing on the surface as a result of imperfections in the structure of sintered materials.

\section{CONCLUSION}

In this study laboratory tests were performed, with particular objectives to:

A. Look into the application of "spark plasma sintering" to produce sintered material useful for practical purposes and manufacturing of sintered materials with zero porosity. In this case, spark plasma sintering allows for the use of the second mode of operation based on the passage of pulsating electric current through the conductive sintered material, a solution that would significantly improve the sintering efficiency of conductive metallic and non-metallic materials.

B. Establish a baseline of values for contact-fatigue life of the sintered steel type Astaloy $\mathrm{CrL}$ for subsequent research in regards to the impact of heat and chemical-heat treatment, the impact of surface treatment by PVD/CVD coatings as well as the DLC type coating. It is particularly concerned with sintered materials with higher density as that which is achieved in conventional sintered materials.

Based on the results of laboratory tests it can be stated that:

1. Applying "spark plasma sintering" technology is suitable for the production of sintered materials with any density, although with the primary aim of achieving density coming up to that of zero porosity. Currently, its use as a substitute for the conventional 
methods is viable only in specific cases only when in a small batch production. It should be noted here that the utilization of operating mode in which a pulsating current flows through the conductive sintered material results in the diffusion of carbon from the carbon paper that separates sintered material from the electrode material. As a result, an increased proportion of carbon in the sintered samples was recorded. In order to obtain samples with the desired carbon amount, it was necessary for the preparation of samples to necessarily involve the proper adjustment of the amount of graphite admixed. The second option was to replace carbon paper by glass fabric which, however, did not have the property of conducting electricity, thereby falling short of the opportunity of sintering by passing a pulsed current through the sample material. Consequently, the material was heated up to the sintering temperature only by the heated outer wall of the carbon matrix.

2. Increasing density results in improved mechanical properties, including resistance to contact fatigue.

3. Lifetime achieved by materials via this technology at the same density is on average longer than by materials produced by standard pressing and sintering affected at the same temperature.

\section{REFERENCES}

[1] Rodziňák, D., Jakubéczyová, D., Zahradníček, V., Hvizdoš, P.: Materials Engineering, vol. 17, 2010, no. 1, p. 23

[2] Čerňan, J., Rodziňák, D., Semrád, K., Zahradníček, R.: Powder Metallurgy Progress, vol. 10, 2010, no. 1, p. 50

[3] Rodziňák, D., Čerňan, J., Semrád, K., Zahradníček, R. In: Proceedings - Poruchy valivých ložísk/Failures of Rolling Bearings, Medzinárodná konferencia/International Conference. Bratislava, 2010, p. 71

[4] Rodziňák, D., Zahradníček, R., Hvizdoš, P., Jakubéczyová, D.: Acta Metalurgica Slovaca, vol. 16, 2010, no. 1, p. 12

[5] Čerňan, J., Rodziňák, D., Semrád, K., Briančin, J.: Powder Metallurgy Progress, vol. 13, 2013, no. 2, p. 63

[6] Čerňan, J., Rodziňák, D., Briančin, J.: Powder Metallurgy, vol. 57, 2014, no. 14, p. 258

[7] Rodziňák, D.: Kovové materiály, vol. 24, 1986, p. 102

[8] Omori, M.: Materials Science and Engineering: A, vol. 287, 2000, no. 2, p. 183 http://dx.doi.org/10.1016/S0921-5093(00)00773-5

[9] Chen, W. et all: Materials Science and Engineering: A, vol. 394, 2005, no. 1-2, p. 132 http://dx.doi.org/10.1016/j.msea.2004.11.020

[10] Anselmi-Tamburini, U. et all: Materials Science and Engineering: A, vol. 394, 2005, no. $1-2$, p. 139

[11] Rodziňák, D. et all: Strojárstvo/Strojírenství, vol. 12, 2010, p. 68 